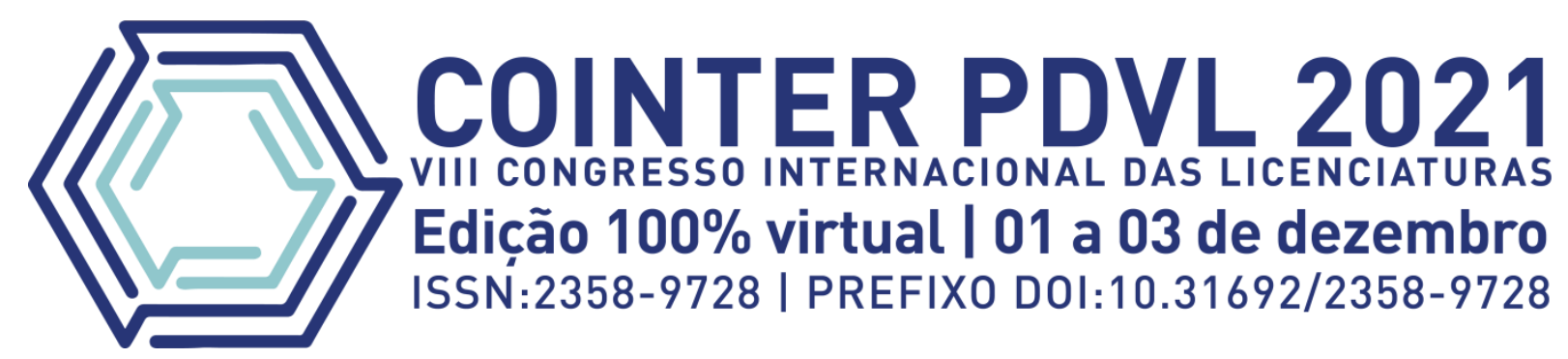

\title{
A PERCEPÇÃO DE DOCENTES ACERCA DA UTILIZAÇÃO DO AMBIENTE VIRTUAL DE APRENDIZAGEM (AVA) NA FORMAÇÃO INICIAL DE PROFESSORES
}

\author{
PERCEPCIÓN DE LOS PROFESORES SOBRE EL USO DEL ENTORNO DE \\ APRENDIZAJE VIRTUAL (AVA) EN LA FORMACIÓN INICIAL DE PROFESORES
}

\section{TEACHERS 'PERCEPTION ABOUT THE USE OF THE VIRTUAL LEARNING ENVIRONMENT (AVA) IN THE INITIAL TEACHER TRAINING}

\author{
Apresentação: Comunicação Oral \\ Áurea Vitória Pereira de Aguiar Silva ${ }^{1}$; Maria Grasielly da Silva Nascimento ${ }^{2}$; Kilma da Silva Lima Viana ${ }^{3}$; \\ Eliemerson de Souza Sales ${ }^{4}$; Etelino José Monteiro Verá Cruz Feijó de Melo ${ }^{5}$
}

DOI: https://doi.org/10.31692/2526-7701.VIIICOINTERPDVL.0282

\begin{abstract}
RESUMO
Neste estudo buscamos analisar a percepção dos professores que atuam na licenciatura em química acerca da utilização de Ambientes Virtuais de Aprendizagem - AVA na formação inicial de professores. A metodologia utilizada foi de caráter qualitativo, tendo como campo de pesquisa uma instituição de ensino superior da rede federal de ensino localizada no interior de Pernambuco. Os participantes foram professores do curso de licenciatura em química que utilizam ambientes virtuais para ofertar cursos aos estudantes. Para coleta dos dados foi utilizada a entrevista estruturada com os professores e análise do Projeto Pedagógico do Curso - PPC do curso de Licenciatura em Química. Foram notáveis as importâncias sobre a utilização do Ambiente Virtual de Aprendizagem - AVA, para formação de professores autônomos e na tomada de decisões, com base nas observações do PPC Projeto Pedagógico do Curso de Licenciatura em Química e também aplicações de entrevistas. Percebeu-se uma reflexão sobre a sua prática e carreira profissional, entendendo que as competências e as habilidades pedagógicas são auxílios favoráveis para melhoria da qualificação quanto ao seu fazer didático-pedagógico e que os professores devem ir em busca de formação para melhor desempenhar o seu trabalho. Além disso, nota-se a importância de uma clara definição epistemológica, a consideração de que os discentes são protagonistas da Internet e por isso a necessidade de promover a autonomia do estudante, a interatividade em ambientes virtuais de aprendizagem e a aprendizagem colaborativa. Ressalta-se, por fim, a importância dessa pesquisa, pois abre uma nova possibilidade de contribuir para
\end{abstract}

\footnotetext{
${ }^{1}$ Licenciando em Química, Instituto Federal de Pernambuco, campus Vitória de Santo Antão, Membro do GEPEC, Membro do PDVL, avpas@discente.ifpe.edu.br.

${ }^{2}$ Licenciando em Química, Instituto Federal de Pernambuco, campus Vitória de Santo Antão, Membro do GEPEC, Membro do PDVL, mariagrasielly2019@gmail.com.

${ }^{3}$ Doutora em Ensino de Ciências, Professora do IFPE, Presidente do IIDV, Coordenadora Geral do PDVL, Líder do GEPEC, kilma.viana@vitoria.ifpe.edu.br e kilma.viana@institutoidv.org.

${ }^{4}$ Mestre em Ensino de Ciências e Matemática (PPQECM/UFPE-CAA), eliemersonsales@gmail.com.

${ }^{5}$ Doutor em Química, Professor do IFPE, Coordenador da Licenciatura em Química do IFPE - campus Vitória, Membro do PDVL e do GEPEC, etelino.melo@vitoria.ifpe.edu.br.
} 


\title{
UTILIZAÇÃO DO AMBIENTE VIRTUAL DE APRENDIZAGEM (AVA) NA FORMACÃO INICIAL DE PROFESSORES
}

a maior discussão acerca da utilização de TIC's - Tecnologia da Informação e Comunicação na Formação do professor.

Palavras-Chave: Tecnologia, ensino, formação de professores, avaliação da aprendizagem, ambiente virtual de aprendizagem- AVA.

\section{RESUMEN}

En este estudio buscamos analizar la percepción de los docentes que laboran en la licenciatura en química sobre el uso de Ambientes Virtuales de Aprendizaje - AVA en la formación inicial de docentes. La metodología utilizada fue de carácter cualitativo, teniendo como campo de investigación una institución de educación superior de la red educativa federal ubicada en el interior de Pernambuco. Los participantes fueron profesores de la carrera de química que utilizan entornos virtuales para ofrecer cursos a los estudiantes. Para la recolección de datos se utilizó una entrevista estructurada con docentes y análisis del Proyecto del Curso Pedagógico - PPC de la Licenciatura en Química. Destacó la importancia del uso del Entorno Virtual de Aprendizaje - AVA, para la formación de profesores autónomos y en la toma de decisiones, a partir de las observaciones del PPC - Proyecto Pedagógico de la Licenciatura en Química y también aplicaciones de entrevistas. Se notó una reflexión sobre su práctica y trayectoria profesional, entendiendo que las destrezas y habilidades pedagógicas son ayudas favorables para mejorar la calificación en cuanto a su práctica didáctico-pedagógica y que los docentes deben ir en busca de formación para desempeñar mejor su labor. trabajo. Además, se destaca la importancia de una clara definición epistemológica, la consideración de que los estudiantes son protagonistas de Internet y por tanto la necesidad de promover la autonomía del estudiante, la interactividad en entornos virtuales de aprendizaje y el aprendizaje colaborativo. Finalmente, se enfatiza la importancia de esta investigación, ya que abre una nueva posibilidad para contribuir a una mayor discusión sobre el uso de las TIC - Tecnologías de la Información y la Comunicación en la Formación Docente.

Palabras Clave: Tecnología, docencia, formación docente, evaluación del aprendizaje, entorno virtual de aprendizaje - VLE.

\begin{abstract}
In this study we seek to analyze the perception of teachers who work in the degree in chemistry about the use of Virtual Learning Environments - AVA in the initial training of teachers. The methodology used was of qualitative character, having as research field a higher education institution of the federal education network located in the interior of Pernambuco. The participants were teachers of the chemistry degree course that use virtual environments to offer courses to students. For data collection, a structured interview with teachers and analysis of the Pedagogical Course Project - PPC of the Chemistry Degree course were used. The importance on the use of the Virtual Learning Environment AVA, for training autonomous teachers and in decision making, based on the observations of the PPC - Pedagogical Project of the Degree in Chemistry and also interview applications were notable. It was noticed a reflection on his practice and professional career, understanding that the pedagogical skills and abilities are favorable aids for improving the qualification regarding his didactic-pedagogical practice and that the teachers should go in search of training to better perform their job. In addition, it is noted the importance of a clear epistemological definition, the consideration that students are protagonists of the Internet and therefore the need to promote student autonomy, interactivity in virtual learning environments and collaborative learning. Finally, the importance of this research is emphasized, as it opens up a new possibility to contribute to a greater discussion about the use of ICTs - Information and Communication Technology in Teacher Education.
\end{abstract}

Keywords: Technology, teaching, teacher training, learning assessment, virtual learning environment - VLE.

\section{INTRODUÇÃO}

Observa-se na atualidade que ambientes virtuais de aprendizagem, conhecidos pela 
sigla AVA, antes utilizados apenas em cursos da modalidade de Educação a Distância (EAD), também passaram a fazer parte da rotina de cursos de modalidade presencial de diversas instituições. Nos cursos de formação inicial de professores, nota-se o crescimento do uso de AVA's tanto como forma de complementação do ensino, bem como é utilizada pela equipe gestora de algumas instituições para desenvolver a formação continuada dos professores.

É importante destacar que, diante das transformações sociais, dos avanços econômicos, tecnológicos e políticos, os métodos tradicionais (MIZUKAMI, 1986) não dão conta da complexidade e da amplitude de conhecimentos produzidos pelo próprio homem. Além disso, a heterogeneidade presente na sala de aula vem solicitando aos professores pensar na multiplicidade de caminhos que favoreçam a aprendizagem dos estudantes. Sobre isso, Silva (2001) aponta que as transformações sociais obriga os professores a repensarem o espaço escolar, percebendo as diversas possibiliddades.

Nessa direação, concordamos com a ideia de que o ensino deve ser focado em uma formação crítica, independente da modalidade e que o uso de Tecnologias da Informação e Comunicação - TICs é um importante instrumento, que contribue para a formação dos estudantes, visto que, está presente em diversas áreas do conhecimento humano (SAEZ, 1999), além de fazer parte do contexto sociocultural de muitos estudantes.

Diante da discussão referente ao ensino a partir do uso de AVA's, as práticas pedagógicas se destacam comos sendo um desafio recorrente a ser enfrentado pelos professores no que se refere ao planejamento e execução. E dentro desse campo de discussão, a avaliação da aprendizagem não poderia ficar de fora dada a sua complexidade. Partimos da concepção de que a avaliação deve apoiar o ensino (proporcionar o desenvolvimento do professor) e potencializar a aprendizagem dos estudantes. Diferentemente de algumas concepções de avaliação que buscam apenas monitorar e informar, recorremos a ideia de que a avaliação deve obrigatoriamente está comprometida com a melhoria da aprendizagem (BELL; COWIE, 2001).

Considerando os desafios supracitados, neste estudo inquieta-nos saber qual a percepção dos professores que atuam na licenciatura em química acerca da utilização de Ambientes Virtuais de Aprendizagem na formação inicial de professores. Para tanto, recorremos inicialmente a investigações bibliográficas em livros e artigos que discutem o tema. Consideramos relevante investigar se no Projeto Pedagógico do Curso - PPC havia alguma orientação acerca do uso do AVA e posteriormente recorremos ao levantamento e análise das percepções dos professores acerca do uso de ambientes virtuais de aprendizagem. 


\section{UTILIZAÇÃO DO AMBIENTE VIRTUAL DE APRENDIZAGEM (AVA) NA FORMACÃO INICIAL DE PROFESSORES}

\section{FUNDAMENTAÇÃO TEÓRICA}

Compreendendo tecnologias, segundo a visão de Sáez (1999): É o conjunto de conhecimentos, relatos e cosmovisões que pressupõe qualquer aplicação técnica presente em diferentes contextos, essas ferramentas na atualidade auxiliam na modificação do meio em que seres-humanos vivem. Tudo pode ser considerado tecnologia desde um giz utilizado para colocar informações em um quadro, quantos computadores e softwares modernos.

A tecnologia surge para facilitar a vida humana e seus afazeres, a partir do século XVIII com a Revolução Industrial e a ascensão do capitalismo. "Tecnologias desenvolvem-se em um ritmo acelerado, até atingir aos dias contemporâneos onde vemos a tecnologia muito mais avançada. Assim, a sociedade cada vez mais se torna tecnológica, inclusive na educação que necessita de especialização de suas ciências" (Ramos, 2012, p.3).

Hoje, o ambiente escolar está permeado da tecnologia (BRASIL). De acordo com Kenski (1996), os professores estão utilizando a tecnologia em suas aulas a cada dia mais e exigindo que os estudantes também utilizem. Gadotti (2002) ressalta que é necessário aprender e ensinar tendo sentido e por isso a importância dos professores se apropriarem das novas tecnologias, pois como diz Morin (2001), não estamos mais vivendo em um mundo com modelos lineares, vivemos em uma sociedade em redes.

De acordo com Ramos (2012, p.6): "Entende-se por tecnologia educacional, o conjunto de técnicas, processos e métodos que utilizam meios digitais e demais recursos como ferramentas de apoio aplicadas ao ensino, com a possibilidade de atuar de forma metódica entre quem ensina e quem aprende."

No entanto, vale salientar que é apontado à resistência dos professores para a possiblidade do uso do AVA por vários motivos, como falta de domínio da tecnologia, a própria falha nos cursos de formação de professores e porque muitos desses professores por serem mais velhos, apresentam dificuldades em manuseio e uso desses equipamentos tecnológicos, por isso preferem utilizar em suas aulas outras metodologias de ensino. Mas é de suma importância que o professor sempre busque se atualizar, pois uma vez que o mundo vem atravessando um grande avanço tecnológico desde a segunda revolução industrial no século XVIII, a escola também precisa acompanhar essas transformações.

O Aprendizado Híbrido apresenta novas possibilidades educacionais, que proveem não apenas a aplicação de recursos para gerenciamento de conteúdos e processos de ensinoaprendizagem em educação à distância, mas também o uso de TICs, na perspectiva de agregar valor a processos de educação presencial. Em outras palavras o conceito de Aprendizado Híbrido se destaca, quando permite a utilização de sistemas de gerenciamento de conteúdo e 
aprendizagem, também conhecidos como Ambientes Virtuais de Aprendizagem e Sistema de Gestão e Aprendizagem, que, até então, eram utilizados, com maior frequência, em práticas de educação à distância e, atualmente, passam a fazer parte da rotina de cursos presenciais.

Salienta-se que, para ensinar é preciso que os professores dominem os conhecimentos de sua área de atuação, articule-os aos saberes experienciais, curriculares, pedagógicos e pessoais e motivem os alunos, por meio de suas estratégias, para que a construção do conhecimento ocorra.

A pertinência das TIC reside, assim, nas dinâmicas da aprendizagem, pois podem não só apoiar a aprendizagem de conteúdos úteis, como desenvolver competências específicas, seja ao nível do software educacional como ao de uso corrente. Sem dúvida que pode ainda auxiliar as capacidades de comunicação (essenciais nos nossos dias!) e, em simultâneo, fomentar a interação e partilha entre os atores educativos, permitindo experiências de ensino e aprendizagem colaborativa e estimulando aptidões essenciais na área da cidadania, incentivando valores como a responsabilidade e a solidariedade. (Silva, 2013).

Decorrente do exposto, Araújo (2007) diz que, o uso da internet amplia as possibilidades de interação, cria novos espaços, novos gêneros discursivos. Além disso, rompe barreiras de tempo, permite fácil acesso a novos conhecimentos e informações, acarretando transformações sociais vertiginosas. Ademais, o mesmo desafia instituições, transforma estruturas, impõe verdadeiros desafios à vida cotidiana, profissional, pessoal. Na sociedade contemporânea ficam evidentes as marcas multiformes ocasionadas pela expansão de fronteiras, pelos encontros interculturais, pela rápida troca de informação.

Os ambientes virtuais de aprendizagem agregam várias tecnologias encontradas na Web para provê a comunicação, disponibilização de materiais e administração do curso. O conjunto de funcionalidades que cada ambiente possui é estabelecido pelos requisitos definidos em cada ambiente. Conforme Gonzales (2005), as funcionalidades dos ambientes virtuais de aprendizagem podem ser organizadas em quatro grupos de ferramentas: de Coordenação, de Comunicação, de Produção dos Alunos ou de Cooperação e de Administração.

Para Sarraf (2012), muitos diretores e professores dizem que o celular é uma ferramenta que atrapalha a aula. Se o aluno usá-lo numa ligação ou mandar uma mensagem, isso pode atrapalhar o conhecimento. E são justamente esses recursos que o professor deve usar como ferramenta pedagógica, não fazer do celular um vilão do ensino. O desafio, então é aproveitar adequadamente os recursos dos aparelhos. Entretanto, o uso do celular na sala de aula pode ser visto como um aliado se usado de forma correta. 


\section{UTILIZAÇÃO DO AMBIENTE VIRTUAL DE APRENDIZAGEM (AVA) NA FORMACÃO INICIAL DE PROFESSORES}

Pensar sobre o professor e sua formação, nos remete a considerar as significativas modificações que se transfiguram na sociedade e em formas que ele pode incorporá-las sem perder sua identidade enquanto educador. A aprendizagem é um processo de construção do aluno, autor de sua aprendizagem, no entanto, o papel do professor é indispensável, pois cabe a ele promover a participação, a comunicação a interação e o confronto de ideias dos alunos, cuidar da "materialidade da ação na base da provocação e da disponibilização da participação livre e plural, do diálogo que gera a co-criação e da articulação de múltiplas informações e conexões" (SILVA, 1994, p. 183).

\section{METODOLOGIA}

Essa pesquisa baseou-se em uma abordagem qualitativa de pesquisa, de natureza exploratório-interpretativa porque, de acordo com Minayo (1994), enfatiza-se o levantamento de informações que permitam apreender o universo de significados, motivos, crenças, valores e atitudes relacionados ao fenômeno estudado, considerando-se, para tanto, o contexto sócio histórico dos participantes do estudo.

Ademais, Alves-Mazzotti e Gewandszbajder (2001, p. 13), estas pesquisas “[...] partem do pressuposto de que as pessoas agem em função de suas crenças, percepções, sentimentos e valores e que seu comportamento tem sempre um sentido, um significado que não dá a conhecer de modo imediato, precisando ser desvelado".

Ainda, segundo Myers (2012), interpretativa porque busca compreender o fenômeno a partir dos próprios dados, das referências fornecidas pelos sujeitos. Contudo, está pesquisa foi feita decorrente do curso de Licenciatura em Química do Instituto Federal de Pernambuco (nosso campo de pesquisa).

Com relação aos procedimentos, iniciamos a pesquisa através de uma revisão de literatura, utilizamos para isso revistas científicas, resumos, anais de congressos, livros, etc. Pois segundo Cardoso (2010, p.7) "cada investigador analisa minuciosamente os trabalhos dos investigadores que o precederam e, só então, compreendido o testemunho que lhe foi confiado, parte equipado para a sua própria aventura".

Em um segundo momento foi analisado o Projeto Pedagógico do Curso de Licenciatura em Química, com foco nas orientações acerca do uso do Ambiente Virtual de Aprendizagem. Em seguida, foram mapeados os componentes curriculares que utilizam plataforma virtual para complementação e/ou aprofundamento dos conteúdos.

Realizamos entrevistas estruturadas com sete professores que ministram disciplinas no curso de Licenciatura em Química no IFPE - Instituto Federal de Pernambuco que vamos 
FORMAÇÃO DE PROFESSORES.

chamar P1, P2, P3, P4, P5, P6 e P7, em que as perguntas eram relativas ao uso do Ambiente Virtual de Aprendizagem (AVA) no curso de Licenciatura em Química.

\section{RESULTADOS E DISCUSSÃO}

\section{O projeto de curso e as orientações acerca do AVA}

foi realizado o mapeamento a partir da análise do Projeto Pedagógico do Curso (PPC) de Licenciatura em Química do IFPE, campus Vitória sobre os componentes curriculares que utilizam plataforma virtual para complementação e/ou aprofundamento dos conteúdos, com foco nas orientações acerca da utilização de carga horária em aulas virtuais. Com isso pode-se notar que, informática, didática, Educação, Ciência, Tecnologia e Trabalho, Mídias Educacionais e Jogos Didáticos para o Ensino da Química são as disciplinas que mais utilizam esse ambiente de aprendizagem.

De acordo com o sexto objetivo específico do PPC - Projeto Pedagógico do Curso de Licenciatura em Química do IFPE - Instituto Federal de Pernambuco - Campus Vitória de Santo Antão mostra que existe uma disponibilidade de fontes de informações relevantes para o ensino da Química para os licenciando, inclusive são disponíveis em duas modalidades, sendo elas eletrônica e remota, possibilitando a contínua atualização técnica, científica, humanística e pedagógica. Diante disso o uso do AVA se constitui como uma ferramenta que cumpre esse objetivo.

Diante do exposto em relação aos saberes docentes, o PPC do curso de Licenciatura em Química traz que o trabalho do docente é lugar de aplicação de saberes produzidos por outros e espaço de produção, transformação e mobilização de saberes que lhe são próprios, ou seja, em outras palavras o professor é sujeito do conhecimento. Ademais, muito se discutem a respeito da formação de professores, em relação aos seus saberes e práticas necessárias para o desempenho da profissão e sobre as mais diversas formas de se medir a capacidade e eficiência desses profissionais.

Ainda de acordo com o PPC da licenciatura em Química ressalta-se que uma das incumbências do licenciado na licenciatura em Química é "analisar o contexto educacional da Educação Básica, nos seus níveis e modalidades de ensino, como futuras possibilidades de atuação profissional articulando-os com diferentes situações-problema frente aos diversos contextos revelados". Com isso pode-se dizer que o papel do egresso é estar apto a atuar em diversas situações, onde é notório que a prática precisa ser constante na perspectiva de busca da formação continuada para melhor desenvolverem suas práticas pedagógicas, logo a busca de aperfeiçoamento contribui positivamente para evolução desse docente e a conquista do seu 


\section{UTILIZAÇÃO DO AMBIENTE VIRTUAL DE APRENDIZAGEM (AVA) NA FORMACÃO INICIAL DE PROFESSORES}

espaço.

Além disso, nota-se que a construção da identidade de um professor é complexa, uma vez que a busca por conhecimentos somente ocorre em alguns deles. Um exemplo disso é a situação a qual o mundo está vivenciando, ou seja, a Pandemia, em que os professores deveriam está aptos a utilizar o ensino de forma remota através do AVA, porém não é o que realmente acontece.

Mas também o projeto pedagógico do curso de licenciatura em Química diz que: “[...] a instrumentação para o ensino de Química compreende os conhecimentos de métodos e técnicas específicas para esse ensino, abordando o uso da tecnologia da informação e comunicação, estudo e revisão de metodologias de ensino de Química e elaboração de projetos de ensino.”.

Vale salientar que os recursos da EaD podem também ser utilizados como suporte ao ensino presencial. Veja o que diz a lei:

Art. $1^{\circ}$. As instituições de ensino superior poderão introduzir, na organização pedagógica e curricular de seus cursos superiores reconhecidos, a oferta de disciplinas integrantes do currículo que utilizem modalidade semi-presencial, com base no art. 81 da Lei n. 9.394, de 1.996, e no disposto nesta Portaria.

$\S 1$ o. Para fins desta Portaria, caracteriza-se a modalidade semi-presencial como quaisquer atividades didáticas, módulos ou unidades de ensino-aprendizagem centrados na autoaprendizagem e com a mediação de recursos didáticos organizados em diferentes suportes de informação que utilizem tecnologias de comunicação remota.

$\S 20$. Poderão ser ofertadas as disciplinas referidas no caput, integral ou parcialmente, desde que esta oferta não ultrapasse $20 \%$ (vinte por cento) da carga horária total do curso.

$\S 30$. As avaliações das disciplinas ofertadas na modalidade referida no caput serão presenciais. 4.

Segundo Moura (1994), a utilização de Tecnologias da Informação e Comunicação (TICs) tem se mostrado um processo irreversível e tal tecnologia pode auxiliar na formação do ser humano, por meio da exploração de práticas pedagógicas mais recentes. A sociedade passa por momentos de transformações e estas mudanças ocorrem devido às novas tecnologias de informação e comunicação, que aos poucos, vão se interligando a atividade educativa. Ademais, as TICs representam ainda um avanço na educação a distância. Com a criação de ambientes virtuais de aprendizagem, os discentes têm a possibilidade de se relacionar, trocando informações e experiências.

Em contextos educacionais está frequente o uso das TICs e com isso, muitos cursos 
presenciais começaram a utilizar também o ambiente virtual de aprendizagem - AVA, como exemplo o curso de Licenciatura em Química do Instituto Federal de Educação, Ciência e Tecnologia de Pernambuco - IFPE - campus Vitória de Santo Antão.

Vale ressaltar, que o AVA auxilia na aprendizagem virtual, pois possibilita a utilização de vários recursos que proporcionam a melhora no ensinamento. Além disso, aprendizagem virtual tem como preocupação maior a formação dos professores que irão atuar com os alunos, possibilitando que os mesmos não só se apropriem das tecnologias que serão usadas, mas saibam como utilizá-las de forma a dinamizar o processo ensino-aprendizagem, uma vez que é possível que os educadores ampliem a relação ensino-aprendizagem, fazendo uso de recursos que diminuam as barreiras físicas e do tempo, indo além da sala de aula convencional, como nos casos dos ambientes virtuais.

Nessa perspectiva a aprendizagem virtual pode envolver materiais multimídias, jogos, atividades para serem realizadas nos computadores ou a mão, entre outras opções, com isso o estudante de graduação passa a agir como sujeito ativo, pessoa humana, exigindo do professor o papel de companheiro na jornada do conhecimento. Salienta-se que essas ferramentas facilitam a interação e motivam o aluno a manter a atenção no curso.

Além disso, procuramos identificar as percepções dos professores sobre a utilização de plataforma virtual nas disciplinas do curso de Licenciatura em Química, a ser apresentado no tópico seguinte.

\section{A percepção dos professores}

Antes de tudo, consideramos relevante conhecer o perfil dos docentes que participaram deste estudo. Nessa direção, a primeira perguntada entrevista ajudou a levantar essas informações. O (quadro 1) apresenta a sistematização do perfil dos professores.

\begin{tabular}{|c|c|c|}
\hline \multicolumn{2}{|c|}{ Quadro 1: Perfil profissional dos participantes da pesquisa } \\
\hline Professores & Formação Inicial & Formação Continuada \\
\hline P1 & Licenciatura em Pedagogia & Doutorado em Educação \\
\hline P2 & Licenciatura em Química & $\begin{array}{c}\text { Mestrado em Química e Doutorando em } \\
\text { Ciências dos Materiais. }\end{array}$ \\
\hline P3 & Engenharia Química & $\begin{array}{c}\text { Especialização em Formação de } \\
\text { Educadores, Mestrado em Tecnologia } \\
\text { Ambiental e Doutorado em Tecnologias } \\
\text { Energéticas e Nucleares. }\end{array}$ \\
\hline P5 & $\begin{array}{c}\text { Bacharel em Sistemas de } \\
\text { Informação }\end{array}$ & $\begin{array}{c}\text { Mestre em Ciência da Computação, } \\
\text { Especialista em Segurança de Redes e } \\
\text { Sistemas. }\end{array}$ \\
\hline P6 & Graduação em Letras & $\begin{array}{c}\text { Especialização em Linguística aplicada ao } \\
\text { ensino de língua inglesa e Mestrado em } \\
\text { Educação Agrícola. }\end{array}$ \\
\hline & Licenciatura em Filosofia & \begin{tabular}{c} 
Especialização em Ciência Política e \\
\hline
\end{tabular}
\end{tabular}




\section{UTILIZAÇÃO DO AMBIENTE VIRTUAL DE APRENDIZAGEM (AVA) NA FORMACÃO INICIAL DE PROFESSORES}

\begin{tabular}{|c|c|c|}
\hline & & Mestrado em Filosofia. \\
\hline P7 & Licenciatura em Matemática & $\begin{array}{c}\text { Especialização em Matemática, } \\
\text { Especialização em Educação Profissional } \\
\text { Técnica na Modalidade PROEJA, } \\
\text { Mestrado Profissional em Matemática em } \\
\text { Rede Nacional (UFRPE). }\end{array}$ \\
\hline
\end{tabular}

Fonte: Própria (2020).

Como exposto no quadro 1, a maioria dos professores possuem formação inicial em curso de Licenciatura, e dentre eles a partir de sua formação continuada podemos inferir que poucos possuem aproximação com a área tecnológica.

Em relação à pergunta "Você conhece o Ambiente Virtual de Aprendizagem (AVA)?", 4 professores disseram que sim e que tem mais familiaridade com a plataforma Moodle, 1 professor disse que conhece, mas utiliza pouco e 2 professores disseram que não conhecem.

Figura 01: Utiliza qual/quais plataformas?

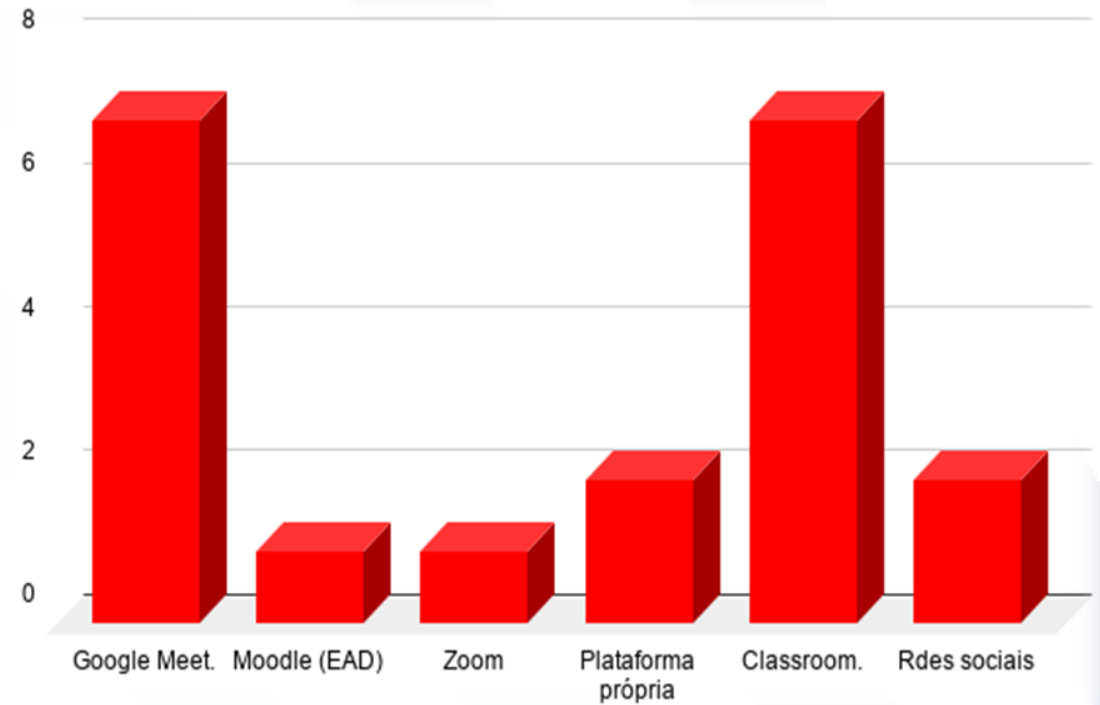

Fonte: Própria (2020).

Baseado nas respostas das perguntas "Utiliza em sua disciplina uma parte de carga horária em aulas virtuais?" e "Utiliza qual/quais plataformas?", pode-se notar que apesar do curso poder utilizar parte de carga horária em aulas virtuais, apenas 1 professor já utilizava em sua disciplina e os outros 6 professores só iriam utilizar a partir das aulas remotas, decorrente do atual cenário que estamos vivenciando, novo normal. Em relação às plataformas são utilizadas e serão utilizados o Google Meet, Plataforma própria, Classroom, redes sociais e o Moodle (EAD) e o Zoom.

Com base nisso, destacamos que essa grande dificuldade dos professores utilizarem o AVA (Ambiente Virtual de Aprendizagem) em suas aulas está relacionada com a escassez de 
profissionais com habilidades e competências voltadas para o uso de tecnologias, a formação de professores em ambiente virtual de aprendizagem pode contribuir para o desenvolvimento de um novo fazer docente. Assim, se o ambiente de aprendizagem se modifica por meio das ferramentas tecnológicas a cada dia, adaptar-se a ele é esperado dos professores e necessário à educação. Sendo assim, é relatado nas respostas dada pergunta "Para você é realmente necessário o uso do AVA? Por quê?”. Observa-se a partir das respostas que a utilização do Ambiente Virtual de Aprendizagem - AVA relacionada à educação ainda há limitações.

Figura 02: Gráfico referente às respostas da pergunta5

\section{Para você é realmente necessário o uso do AVA?}

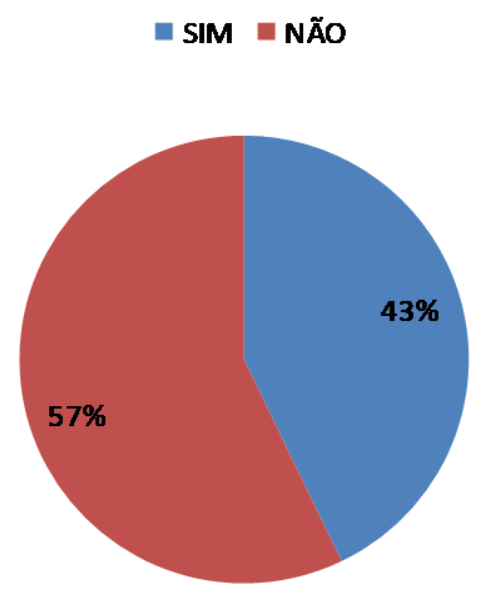

Fonte: Própria (2020)

Nota-se que dos sete professores, apenas quatro considera necessário o uso do AVA Ambiente Virtual de Aprendizagem, como podemos ver nas falas abaixo:

P1: "Não, mas a utilização de opções diversificadas favorece o desenvolvimento do processo de ensino e aprendizagem na atualidade.".

P2: "No atual contexto, sim.".

P3: "Sim, acredito que o professor é capaz de atingir toda sua capacidade de mediação.”.

P4: "Sim, facilita a aprendizagem e fica mais fácil a modelagem de alguns elementos da aprendizagem.".

P5: "Ainda não tenho resposta bem fundamentada. Mas creio que haja limitações sobre a educação.".

P6: "É útil e cada vez mais incontornável o ambiente virtual. Acho importante para complementação ou aprofundamento de conteúdo. Também pode ser usado para preencher lacuna de aprendizado durante o processo.".

P7: "Não, mas pode facilitar o processo de ensino-aprendizagem.".

Fazendo refêrencia a fala de P1, P2, P3, P4, P5, P6 e P7, deve-se entender que além da capacidade de uma série de saberes, o professor da universidade como docente exerce um 


\section{UTILIZAÇÃO DO AMBIENTE VIRTUAL DE APRENDIZAGEM (AVA) NA FORMACÃO INICIAL DE PROFESSORES}

importantissimo papel com o que diz respeito ao conhecimento, onde a informação acontece em grande escala e alta velocidade, o que amplifica as exigências em relação a este profissional sobre o poder das TICS - Tecnologias da Informação e Comunicação evidentes de modo especial na vida dos jovens universitários. Em outras palavras a evolução da tecnologia trará para os ambientes de aprendizagem grandes avanços pedagógicos, institucionais e gerenciais.

Também foi possível analisar pelas respostas dos professores na pergunta "Em relação ao desempenho dos discentes através do AVA, você acredita que contribui para o ensinoaprendizagem? Por quê?", que precisa de um acompanhamento mais extensivo de todo processo a fim de diagnosticar situações que possam ser reestruturadas em tempo viável sem interferência na aprendizagem construída, que sendo bem utilizado, pode contribuir sim. Por se mostrar um meio possível no contexto atual e pelas facilidades que ele apresenta na utilização de novas metodologias mediadas por ele, por exemplo, tais salas de aula invertida, projetos e etc.

Ademais, os ambientes virtuais proporcionam a possibilidade de ultrapassar a sala de aula, no sentido de corrigir e aprofundar o que foi visto presencialmente. No entanto ainda há muitos questionamentos sobre ensino-aprendizagem. Vale ressaltar que cabe a cada discente o seu desempenho, pois cada um sabe qual é o seu objetivo e o quanto está comprometido com ele.

É oportuno frisar que Segundo Moran (1997), a Internet está explodindo como a mídia mais promissora desde a implantação da televisão. Instituições educacionais estão buscando esses novos recursos tecnológicos para a criação de ambientes de aprendizagem para uso educacional, designados de ambientes virtuais de aprendizagem. Diante disso, a interface num Ambiente Virtual de Aprendizagem deve possibilitar a construção de conteúdos, gestão de base de dados, controle de informações que circulam no ambiente e canais diversos de comunicação.

São aspectos relevantes para incrementar a motivação dos alunos, despertar o interesse dos alunos, a facilidade de navegação e o desenho simples da interface, deste modo, mantendo o AVA sempre atrativo. Parafraseando Nóvoa (1995), a formação não se constrói por acumulação de cursos, de conhecimentos ou de técnicas, mas sim através de um trabalho de reflexividade crítica sobre as práticas de (re) construção permanente de uma identidade pessoal.

Tori (2010) destaca a adoção de sistemas de gerenciamento de conteúdo e aprendizagem em contextos híbridos de educação tanto presencial como a distância. É notório 
que na década de 90, a introdução das tecnologias e da internet na educação permitiram positivamente na interatividade, formando assim redes de aprendizagem cooperativa, com o uso de recursos digitais síncronos e assíncronos, além de serem integrados aos outros recursos já utilizados anteriormente.

A modalidade EAD foi potencializada, culminando em uma educação cada vez mais perto e mais personalizada, na qual os sujeitos envolvidos têm o relativo privilégio de escolher a melhor forma de ensinar (ou aprender), além de privilegiar a permuta de conhecimentos em rede. Ademais, o AVA - Ambiente Virtual de Aprendizagem, é um sistema ou software que proporciona o desenvolvimento de conteúdos.

Além disso, um AVA pode ser usado também como ferramenta para EAD (educação a distância) e como o caso do IFPE - Instituto Federal de Pernambuco - campus Vitória de Santo Antão que utiliza o mesmo para complementar aulas presenciais com conteúdos virtuais..

\section{CONCLUSÕES}

Sabemos que nos dias de hoje, as tecnologias da informação e da comunicação (TIC) norteiam as ações e as relações das pessoas no âmbito da família, do trabalho, dos negócios, dos estudos, do lazer, entre outros. Nessa sociedade, para ser cidadão do mundo é preciso se manter atualizado por meio da formação continuada. A Educação a distância (EaD), ao utilizar recursos da web para suportar essa formação, permite aos cidadãos ampliar seus espaços de partilha e aprendizagem, ao mesmo tempo em que flexibiliza os momentos de estudo dos mesmos.

Essa pesquisa teve como objetivo abordar como os docentes do curso de licenciatura em Química do IFPE utilizavam os recursos tecnológicos em suas aulas para complementação ou aprofundamento dos componentes curriculares, apontando as percepções dos professores sobre a utilização da plataforma virtual na Licenciatura em Química e colaborar no desempenho do professor como no aprendizado dos estudantes. Além disso, apresentar que utilizar tecnologias nas aulas, não significa que as aulas vão ser boas e construtivas, mas que é necessário utilizar outras metodologias para assim desperte a curiosidade do educando. Sento assim, espera-se que esta pesquisa possa contribuir de maneira significativa, como um recurso de informação para a formação de professores. Em que os docentes possam repensar suas práticas e busque auxiliar o aluno se formar pessoas críticas, fugindo do modelo bancário de ensino.

Decorrente do exposto, podemos concluir que a possibilidade da utilização de novas 


\section{UTILIZAÇÃO DO AMBIENTE VIRTUAL DE APRENDIZAGEM (AVA) NA FORMACÃO INICIAL DE PROFESSORES}

tecnologias relacionadas ao ensino é um recurso colaborativo no ensino da Licenciatura em Química. É notório que essa pesquisa teve um impacto direto de forma positiva nos sujeitos envolvidos auxiliando-os na aprendizagem do uso do AVA - Ambiente Virtual de Aprendizagem. Enfatizamos que a maioria dos professores envolvidos na pesquisa mencionou não utilizar com tanta frequência ou não utilizar o AVA, pois não tinham familiaridade com o ambiente virtual, não viam necessidade de utilizar o mesmo e até mesmo pela falta de tempo na organização das aulas virtuais. O que é lícito ressaltar que há o interesse dos professores em utilizar o Ambiente Virtual de Aprendizagem a partir da reclusão, ou seja, aulas remotas.

Além disso, no que se refere à atribuição de papéis durante o trabalho com um AVA, o professor ocupa posição central na mediação pedagógica, na organização do ambiente virtual, buscando adequá-lo ao cumprimento dos objetivos do curso e no incentivo à participação e interação. No entanto, ele não é o único a influenciar a construção do conhecimento dos alunos, pois também os demais participantes desempenham função notória no processo. Foi compreendido que é necessário que os mesmos além de conhecer a importância do AVA busque se capacitar mais e aproveitar todas as ferramentas que a instituição possui como computadores, internet, laboratório, Google Meet, Classroom, Moodle e outros recursos tecnológicos, pois isso pode contribuir muito para o ensino-aprendizagem dos discentes.

Concluímos que a possibilidade da utilização de novas tecnologias relacionadas ao ensino é um recurso colaborativo no ensino da Licenciatura em Química. A utilização destas permite uma nova possibilidade de interação e aprendizado, tanto na assimilação de conceitos, habilidades e competências por parte dos estudantes, quanto no sentido de possibilitar aos professores analisarem melhor as implicações entre as diferentes representações, contribuindo, portanto, para a aprendizagem mais significativa na Química.

Além disso, podemos afirmar que reuniões sistemáticas de professores universitários, sob coordenação pedagógica, podem ampliar os sentidos e significados da prática docente, influenciando positivamente em nossa tomada de decisão que precisa se orientar pela crença nos efeitos de nossa ação nos alunos, na flexibilidade para respondermos às imprevisibilidades do cotidiano, na nossa consciência que revela o conhecimento que temos de nós mesmos e do contexto no qual estamos inseridos. Um AVA consiste em uma ou mais soluções de comunicação, gestão e aprendizado eletrônico, que possibilitam o desenvolvimento, integração e a utilização de conteúdos, mídias e estratégias de ensinoaprendizagem.

\section{REFERÊNCIAS}


ALMEIDA, M. E. B. Educação a Distância na Internet: abordagens e contribuições dos ambientes digitais de aprendizagem. Revista Educação e Pesquisa, São Paulo, v. 29, n. 2, p. 327-340, 2003.

BELL, B., \& COWIE, B. The characteristics of formative assessment in science education. Science Education, 85, 536-553, 2001.

BELLONI, Maria Luiza. Educação à distância. 2. ed. Campinas, SP: Autores Associados, 2001. p.115

BORSATTO, Paulo C. Avaliação da aprendizagem em educação online na Universidade Corporativa. Rio de Janeiro. 2007. Domínio Público. Teses.

CARDOSO. A.; LAMOUNIER JÚNIOR, E. Aplicações de Realidade Virtual e Realidade Aumentada na Educação e Treinamento. In: Pré-Simpósio SVR, Porto Alegre, PUC-RS, 25 28 mai. 2009. Aplicações de Realidade Virtual e Aumentada. COSTA, R. M.; RIBEIRO, M. V. (Org.). Porto Alegre: SBC, 2009. cap. 3, p. 53-68.

GUBA, E. G.; LINCOLN, Y. S. Fourth generation evaluation. Newbury Park, London, New Delhi: Sage, 1989.

HADJI, Charles. Avaliação desmistificada. Porto Alegre: Ed. Artmed. 2001.

HOFFMAN, J. Avaliação mediadora: uma prática em construção da pré-escola à universidade. Porto Alegre: Mediação, 2001.

HOFFMAN, Jussara. Avaliação Mediadora 8. ed. Porto Alegre: Ed. Artmed, 2004.

LIMA, K. S. Compreendendo as concepções de avaliação de professores de física através da teoria dos construtos pessoais. Recife, 2008. 163 p. Dissertação (Ensino das Ciências). Departamento de Educação, UFRPE, 2008.

MORAN, José Manuel. Avaliação da EaD no Brasil. Disponível em: http://www.eca.usp.br/prof/moran/avaliacao.htm. Acesso em: 14/05/2008.

NARDI, R.; CORTELLA, B. S. C. Formação de professores de Física: das intenções legais ao discurso dos formadores. In: XVI Simpósio Nacional de Ensino de Física, 2005, Rio de Janeiro. Caderno de Resumos. São Paulo - SP: Sociedade Brasileira de Física, 2005. v. 1. p. 175-175, 2005.

Saéz, V.M.M. Globalización, Nuevas Tecnologias y Comunicación. Madrid: Ediciones de La Torre, 1999.

SALES, E. S.; MONTEIRO, I. G. S.; LIMA, K. S. Formação de professor, diretrizes da Educação brasileira para o ensino de Química e Avaliação: saberes docentes essenciais à formação docente. In: VII Colóquio Internacional Educação e Contemporaneidade, 2013, São Cristóvão - SE. Anais do Colóquio Internacional Educação e Contemporaneidade, 2013.

SETZER, Valdemar. Uma revisão de Argumentos a favor de uso de computador na educação no Brasil - Disponível em: www.ime.usp.br Acesso em: 01/09/2021. 


\section{UTILIZAÇÃO DO AMBIENTE VIRTUAL DE APRENDIZAGEM (AVA) NA FORMACÃO INICIAL DE PROFESSORES}

SILVA, Cecília Pereira da. A paixão de Formar - da psicanálise à Educação. Artes Médicas, São Paulo, 1994.

VASCONCELLOS, Celso dos Santos. Avaliação: Concepção Dialética-Libertadora do Processo de Avaliação Escolar. São Paulo; Libertad,1994. 